\title{
Removal of Heavy Metal Ions Using Polystyrene Nanocomposite Thin Films
}

\author{
Mashael Alshabanat \\ Department of Chemistry, Faculty of Science, Princess Nourahbint Abdulrahman \\ University, Riyadh, KSA, Riyadh, P.O.B. 84428
}

\begin{abstract}
DOLYMER nanocomposite thin films consisting of polystyrene and furnace carbon black were prepared in this study as adsorbent materials for the removal of heavy metals from industrial wastewater. The film properties were characterized, and the effect of initial concentration, separation time, and $\mathrm{pH}$ on the removal efficiency was investigated. The optimal operating conditions were $120 \mathrm{~min}$ of separation time at $\mathrm{pH} 6$ with $30 \mathrm{ppm}$ of initial concentration. The adsorption equilibrium data and adsorption kinetics are also described herein. The Freundlich model best fit the equilibrium data, and the adsorption rate followed pseudo second-order kinetics.
\end{abstract}

Keywords: Removal, Polymer nanocomposite, Pollution, Thin film.

\section{Introduction}

Heavy metals are dangerous environmental contaminants and pose a threat to human health. As an example of the danger of heavy metals, the mercury contamination of Minamata city must be mentioned. This incident was one of the most significant environmental disasters, because of which mercury poisoning came to be known as the Minamata disease, signifying the risk that heavy metal contamination poses. The dangerousness of heavy metals comes from their tendency to accumulate[1], and various human activities can cause heavy metal pollution. The sources of heavy metals can be classified into five major categories: geochemical; agricultural impurities, pesticides, and metal corrosion; metallurgical industry from manufacturing and recycling of alloys; waste disposal from landfills and incinerators; and other manufacturing sources such as batteries and paints[1].

Scientists realized the issue of heavy metal contamination long ago and have focused their efforts on finding efficient methods to remove these pollutants and develop effective materials for this purpose. Coagulation, flotation, chemical oxidation, and adsorption are examples of techniques used for treating wastewater [2,3]. The adsorption of pollutants is preferable because it is efficient and can separate many chemicals simply and effectively [4]. Many research groups have focused on developing novel materials with improved efficiency and acceptable cost, utilizing materials such as biomass [5-8],clay $[9,10]$, waste materials, [3,11] and polymer nanocomposites $[2,12]$.

The need to further develop materials for heavy metal removal is ongoing. Acceptable cost with efficient performance and the ease of operation are the most important parameters for any new adsorbents for commercial production. Therefore, polymer nanocomposite thin films are an attractive alternative to conventional materials.

In our previously published work [13], nanocomposite films of polystyrene and nanoparticles of furnace carbon black were prepared via simple mixing process and characterized spectroscopically, microscopically, electrically and mechanically. This work comes to be an applied study of it to examine their adsorbability and applicability for the removal of lead $\left(\mathrm{Pb}^{+2}\right)$ from a heavy metal-contaminated target under various operational conditions, such as the content filler in the composites, lead concentration, separation time, and $\mathrm{pH}$ were tested to determine the optimal operating conditions.

\section{Experimental}

Materials and preparation method of the film were reported in our previous study in details [13], with slight changes to the filler content to achieve the aims of this study.

Corresponding author e-mail: ma.naif@hotmail.com

DOI: 10.21608/EJCHEM.2018.4056.1354

C2017 National Information and Documentation Center (NIDOC) 


\section{Materials}

Matrix: Polystyrene from Sabic Co. There are different grades produced of polystyrene by the company, and the used product was PS330.

Reinforcement: Furnace carbon black (FCB) from Degussa Co., and the data of this product as follows [13]:

$\mathrm{pH}$ is 7 , ash content is $0.05 \%$, volatiles is $1.0 \%$ and particle size is $95 \mathrm{~nm}$.

Solvent: Toluene from BDH Co. was chosen because of it less toxic than the other solvent such as benzene, and completely dissolve the polystyrene without any clump of solid PS could be left behind, not as noted with the acetone solvent after evaporating. For environmental considerations, D- limonene is suggested as a natural solvent [14].

\section{Methods}

To prepare the film, preparative method as reported in our previous study [13] was followed. A suspension of FCB in $50 \mathrm{~mL}$ of the solvent was stirred magnetically for $1 \mathrm{~h}$, and then $5 \mathrm{~g}$ of the polymer was added and stirred at $50^{\circ} \mathrm{C}$ for further $60 \mathrm{~min}$. Subsequently, the mixture was cast on a glass slide and left for the solvent to evaporate at ambient temperature. The ratio of the furnace carbon black to polymer was $15 \mathrm{wt} \%$ for the prepared films.

Several analyses were performed to characterize the properties of the film, including tensile testing using an Instron Corporation Model 8500 materials instrument according to D882-02, and thermal stability using a PerkinElmer Thermal Analysis Systems-TGA 7 Thermogravimetric Analyzer at a heating rate of $10{ }^{\circ} \mathrm{C} / \mathrm{min}$ from $25^{\circ} \mathrm{C}$ to $600{ }^{\circ} \mathrm{C}$ under a nitrogen atmosphere, surface area was determined using a Nova analyzer (Quantachrome Instrument version 2.1) by measuring the BET and Langmuir adsorption isotherms for Nitrogen gas adsorption, and the morphology of the film surface before and after the removal process was analyzed using SEM (Quanta 250) to observe any changes could be obtained.

Lead removal studies were performed with various concentrations of lead ions. The experiments were performed by immersing a piece of the film with an area equal to $4 \mathrm{~cm}^{2}$ into the lead ion solutions, followed by continuous agitation for a specific time. Subsequently, the film was removed, and the samples were analyzed using Egypt.J.Chem. 62, No. 1 (2019)
PC-controlled double-beam atomic spectroscopy (SavantAA GBC with GF 5000 Graphite Furnace, UK).

The conditions of the experiments were designed to study the influence of the following factors:

1. Initial concentration of lead ion solutions: This factor was investigated using a series of the lead solutions with concentrations equal to 5 , $10,15,20,3,50 \mathrm{ppm}$ at constant conditions of $\mathrm{pH} 5,120 \mathrm{~min}$ separation time, and at $25^{\circ} \mathrm{C}$.

2. Separation time: This factor was tested by performing the reaction for $15,30,60,90$, 120 , and $180 \mathrm{~min}$ at fixed conditions of $\mathrm{pH} 5$, $30 \mathrm{ppm}$ lead solution, and at $25^{\circ} \mathrm{C}$.

3. $\mathrm{pH}$ : This factor was also investigated by adjusting the lead solution to a $\mathrm{pH}$ of $4,5,6,7$, 8, or 9 using a Hydrolab sensor (WTW Multi 340i Set, Germany) under constant conditions of $30 \mathrm{ppm}$ lead solution, separation time of $120 \mathrm{~min}$, and at $25^{\circ} \mathrm{C}$.

Experiments were repeated three times. Mean and standard deviation values were calculated. Furthermore, in all experiments, the percentage removal was calculated using the following equation [7]:

$$
R(\%)=\frac{\left(C_{\mathbf{0}}-C_{e}\right) \times 10 \mathbf{0}}{C_{\mathbf{0}}}(1)
$$

where $C_{0}$ and $C_{\mathrm{e}}$ are the initial concentration of the lead solution and the lead concentration at equilibrium, respectively.

Adsorption capacity of the adsorbent was calculated using (Eq. (2)), and adsorption isotherms were estimated; namely, Langmuir (Eq. (3)) and Freundlich (Eq. (4)) models.

$$
q_{e}=\frac{\left(C_{\mathrm{o}}-C_{e}\right) \times V}{M}
$$

where $C_{0}$ and $C_{\mathrm{e}}$ were defined in Eq. (1), and $V$ and $M$ are the volume (L) of the initial lead solution and mass $(\mathrm{g})$ of the film, respectively. A recorded value of $C_{\mathrm{e}}$ was the average value of three experimental readings.

$$
\begin{gathered}
C_{\mathrm{e}} / q_{\mathrm{e}}=1 / b q_{\mathrm{m}}+C_{\mathrm{e}} / q_{\mathrm{m}} \\
\log q_{e}=K_{\mathrm{f}}+1 / n \log C_{e}
\end{gathered}
$$

where $q_{m}$ and $b$ are the Langmuir constants, and $n$ and $K_{\mathrm{f}}$ are the Freundlich constants. To study the 
adsorption rate, pseudo first and second-orders models of kinetic as expressed by Eq. (5) [15] and Eq. (6) [16], respectively.

$$
\begin{aligned}
\log \left(q_{e} / q_{\mathrm{t}}\right) & =\log q_{\mathrm{e}}-\left(k_{l} \mathrm{t} / 2.303\right) \\
\left(t / q_{\mathrm{t}}\right) & =\left(1 / k_{2}\left(q_{e}\right)^{2}\right)+\left(t / q_{e}\right)(6)
\end{aligned}
$$

where $k_{1}$ and $k_{2}$ are the adsorption rate constant of pseudo-first and second orders, respectively.

\section{Results and Discussion}

The characteristics of the prepared film are summarized in Table 1. Figure 1 shows the SEM images of the FCB in (a), and the film before and after the removal process in (b) and (c), respectively. Regular spherical particles of the furnace carbon black were observed. Before the removal process, some aggregation of the FCB particles was noted of the surface of the film. After removal, shiny particles in star shape were clearly observed on the surface, which can be attributed to the adsorbed lead ions.
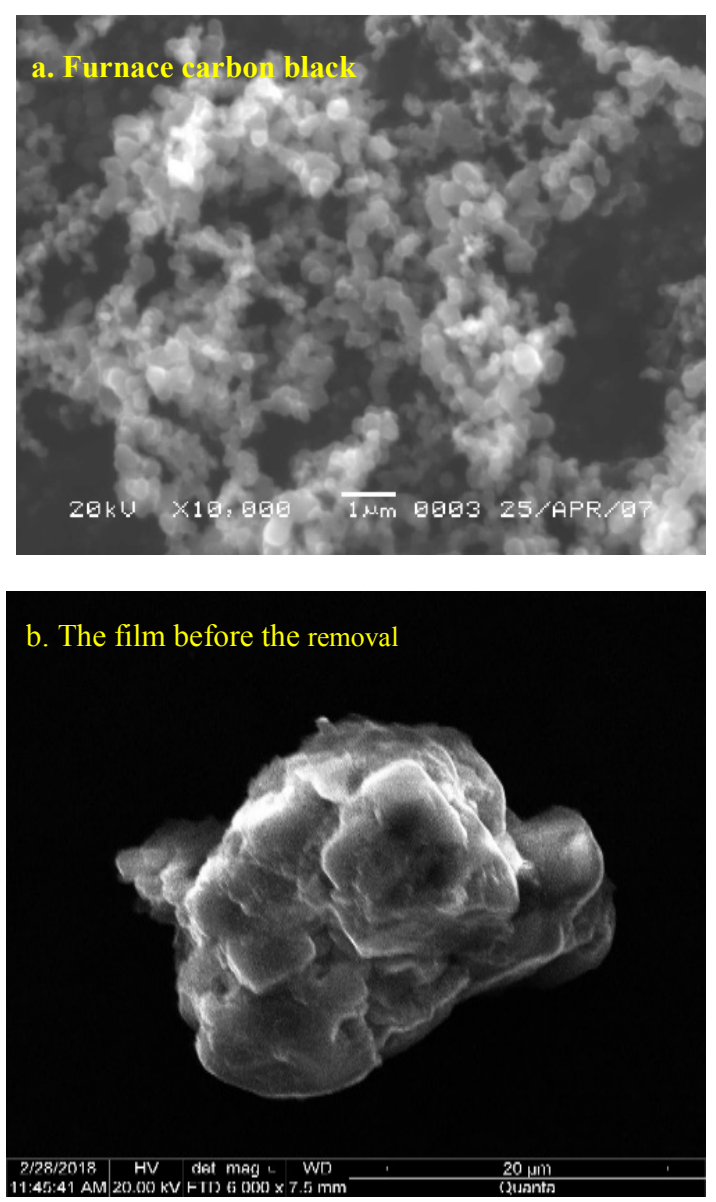

TABLE 1. The characteristics of the thin film

\begin{tabular}{|c|c|c|}
\hline \multicolumn{2}{|c|}{ Surface area $\left(\mathrm{m}^{2} / \mathrm{g}\right)$} & \multirow{2}{*}{$\begin{array}{c}\text { Tensile } \\
\text { strength (MPa) }\end{array}$} \\
\cline { 1 - 2 } Langmuir & BET & \\
\hline 33.18 & 21.76 & 21.6 \\
\hline
\end{tabular}

Figure 2 shows the thermogravimetry curve of the film, which provides information about the thermal stability of the film. The thermal degradation of the film occurs in one step, from about 390 to $450{ }^{\circ} \mathrm{C}$, while the polymer from 388.07 to $423.9{ }^{\circ} \mathrm{C}$. It was notable that the nanocomposite film was more thermally stable than the original polymer itself, and this may because the aggregation of the carbon particles acts as a barrier against the diffusion of polystyrene degradation products into gas phase.
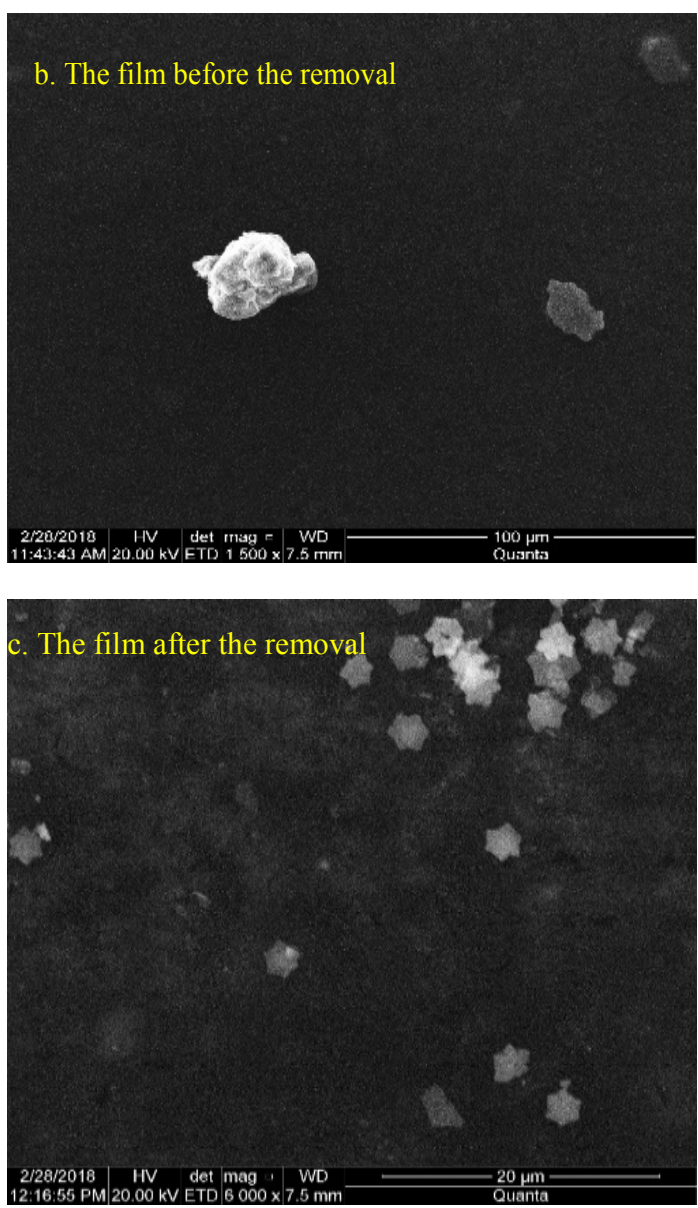

Fig. 1. SEM images of the furnace carbon black in (a), the film before removal (b), and the film after the removal process (c). 


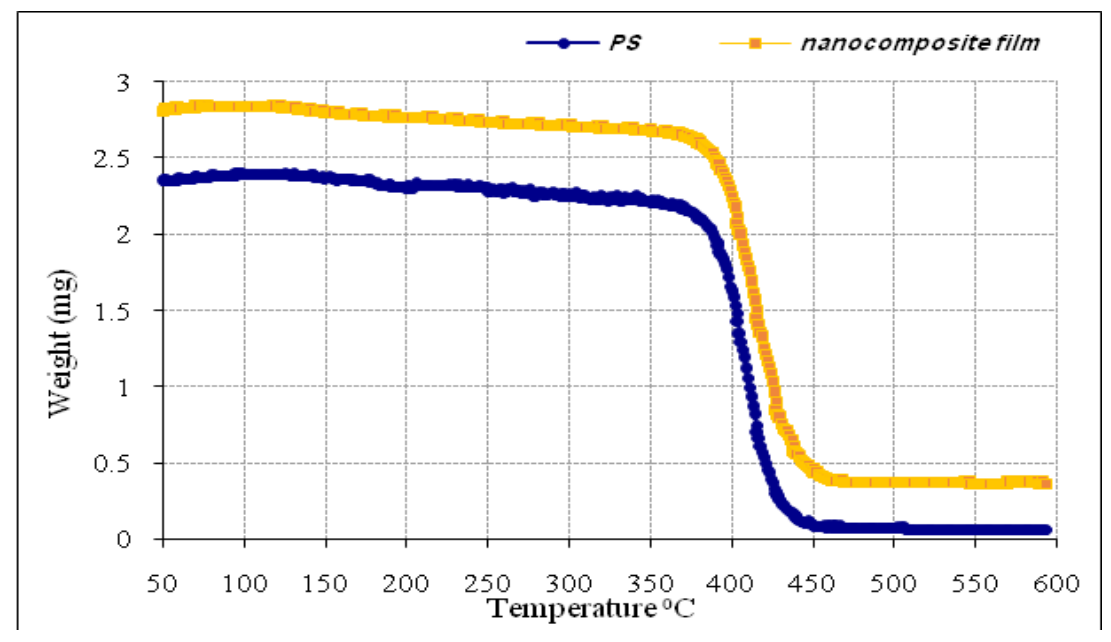

Fig. 2. The thermogravimetry curve of the film.

The lead removal data are summarized in Tables 2-4 and the results are illustrated in Fig. 3-5.

The effect of the initial concentration of lead on its percentage removal is shown in Fig. 3 . The lead removal occurs into two steps; the first ends at a lead concentration of 20 ppm followed by the second step. The results suggest more than monolayer adsorption mechanism for the removal of lead ions. In first step, percentage removal increases because of the availability of the adsorption sites on the surface, after which decreases because of saturation the active sites. New surface of adsorption could be formed by this layer; therefore, notable increase in percentage removal with increasing the concentration, forming new layer of adsorption in a second step.

Figure 4 shows the effect of separation time on the lead removal efficiency. Because the active

TABLE 2. Data of the removal process as a function of initial concentration.

\begin{tabular}{|c|c|c|c|}
\hline $\begin{array}{c}\text { Removal } \\
(\%)\end{array}$ & $\begin{array}{c}\text { Slandered } \\
\text { Deviation }\end{array}$ & $\begin{array}{c}\mathbf{C}_{\mathbf{e}} \\
(\mathbf{p p m})\end{array}$ & $\begin{array}{c}\mathbf{C}_{\mathbf{o}} \\
\mathbf{( p p m )}\end{array}$ \\
\hline $68.9 \%$ & 0.06 & 1.56 & 5 \\
\hline $77.3 \%$ & 0.49 & 2.27 & 10 \\
\hline $75.4 \%$ & 0.26 & 3.68 & 15 \\
\hline $74.6 \%$ & 0.85 & 5.08 & 20 \\
\hline $85.6 \%$ & 0.78 & 4.32 & 30 \\
\hline $84.3 \%$ & 0.57 & 7.86 & 50 \\
\hline
\end{tabular}

sites for adsorption have not saturated yet, the percentage removal increases gradually with increasing the separation time until $120 \mathrm{~min}$, then slows due to saturation of the adsorption site [17].

Figure 5 shows the percentage removal of lead as a function of $\mathrm{pH}$. The best medium for lead removal was at $\mathrm{pH}$ 6, whereas in the strongly acidic and alkaline media, the percentage removal was reduced. In the acidic medium, protonation process occurred; thereby, the adsorption of protons $\left(\mathrm{H}^{+}\right)$competes with the adsorption of positively charged lead ions [14], whereas in the alkaline medium, the adsorption of lead may be inhibited by the formation of lead hydroxide complex because of the excessive ions of hydroxyl [17], leading to reduce the percentage removal.

TABLE 3. Data of the removal process as a function of separation time, $C_{0}$ was $30 \mathrm{ppm}$.

\begin{tabular}{|c|c|c|c|}
\hline $\begin{array}{c}\text { Removal } \\
(\mathbf{\%})\end{array}$ & $\begin{array}{c}\text { Slandered } \\
\text { Deviation }\end{array}$ & $\begin{array}{c}\mathbf{C}_{\mathrm{e}} \\
(\mathbf{p p m})\end{array}$ & $\begin{array}{c}\text { Separation } \\
\text { time (min) }\end{array}$ \\
\hline 38.9 & 0.91 & 18.32 & 15 \\
\hline 50.1 & 0.79 & 14.97 & 30 \\
\hline 65.1 & 1.00 & 10.47 & 60 \\
\hline 70.4 & 1.18 & 8.87 & 90 \\
\hline 85.6 & 0.78 & 4.32 & 120 \\
\hline 80.1 & 0.87 & 5.98 & 180 \\
\hline
\end{tabular}

Egypt.J.Chem. 62, No. 1 (2019) 
TABLE 4. Data of the removal process as a function of pH, Co was 30 ppm.

\begin{tabular}{|c|c|c|c|}
\hline $\begin{array}{c}\text { Removal } \\
(\mathbf{\%})\end{array}$ & $\begin{array}{c}\text { Slandered } \\
\text { Deviation }\end{array}$ & $\begin{array}{c}\mathbf{C}_{\mathbf{e}} \\
(\mathbf{p p m})\end{array}$ & $\mathbf{p H}$ \\
\hline 65.1 & 1.18 & 10.47 & 4 \\
\hline 71.4 & 0.79 & 8.57 & 5 \\
\hline 86.1 & 0.33 & 4.18 & 6 \\
\hline 59.7 & 0.72 & 12.09 & 8 \\
\hline 49.7 & 1.87 & 15.08 & 9 \\
\hline
\end{tabular}

To determine the underlying mechanism of lead removal, experimental adsorption data were analyzed and described by Langmuir (Eq. (3)) and Freundlich (Eq. (4)) adsorption isotherms models. Plotting $\left(\mathrm{C}_{\mathrm{e}} / \mathrm{q}_{\mathrm{e}}\right)$ vs $\mathrm{C}_{\mathrm{e}}$ of the Langmuir model and $\log q_{e}$ vs $\log C_{e}$ of the Freundlich model should produce straight lines. The correlation coefficients $\left(R^{2}\right)$ of the linearity relationship govern their suitability for describing the adsorption. A comparison of the obtained $R^{2}$ values from both plots 0.5638 for the Langmuir (not shown) and 0.9969 for the Freundlich model (Fig. 6) suggests that the experimental data of lead adsorption best fit the Freundlich model with a $K_{f}$ of $1.53 \mathrm{mg} / \mathrm{g}, n$ of 0.69 , and $1 / n$ of 1.449 .

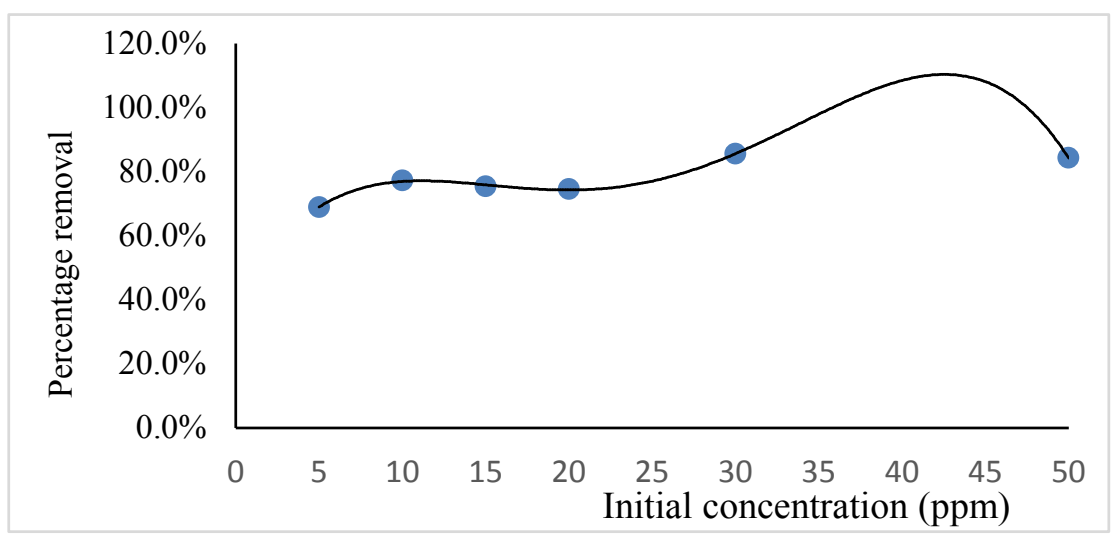

Fig. 3. The effect of initial concentration on the removal process.

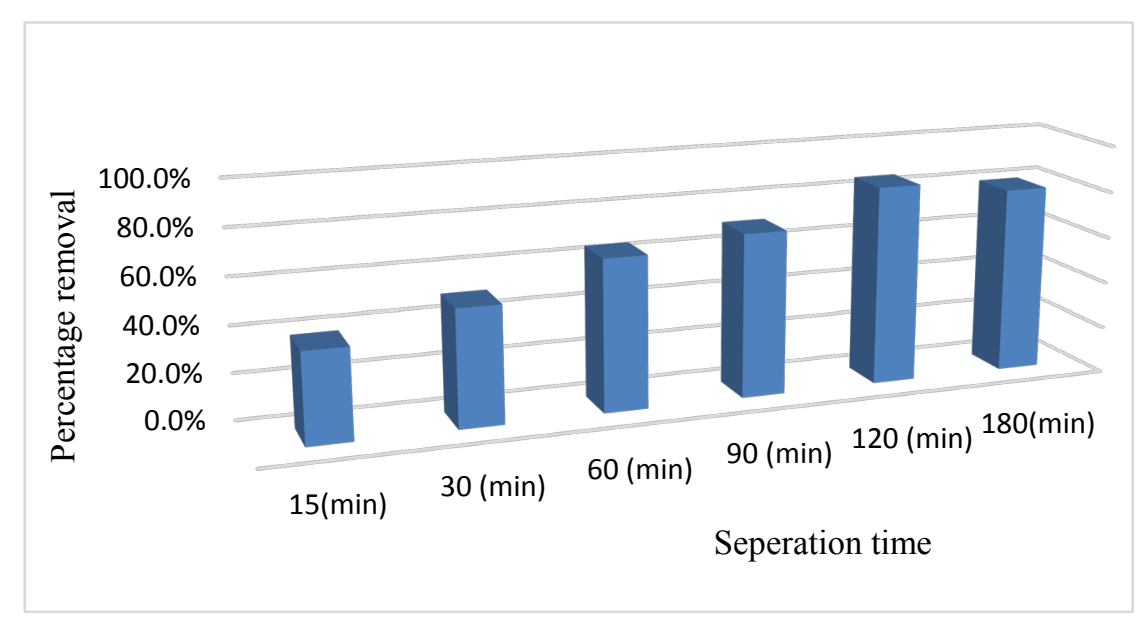

Fig. 4. The effect of separation time on the removal process. 


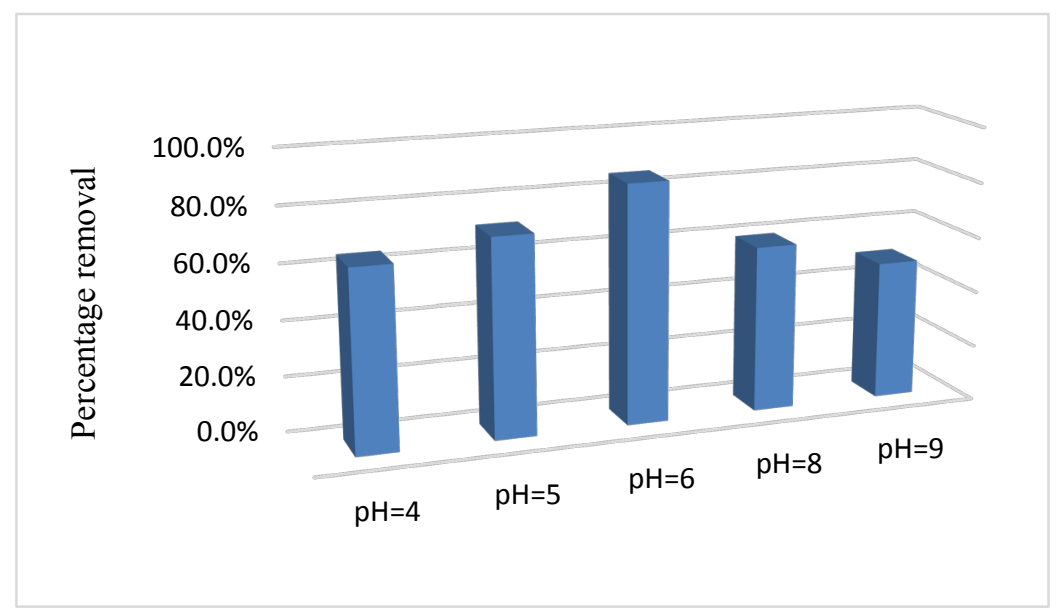

Fig. 5. The effect of $\mathrm{pH}$ on the removal process.

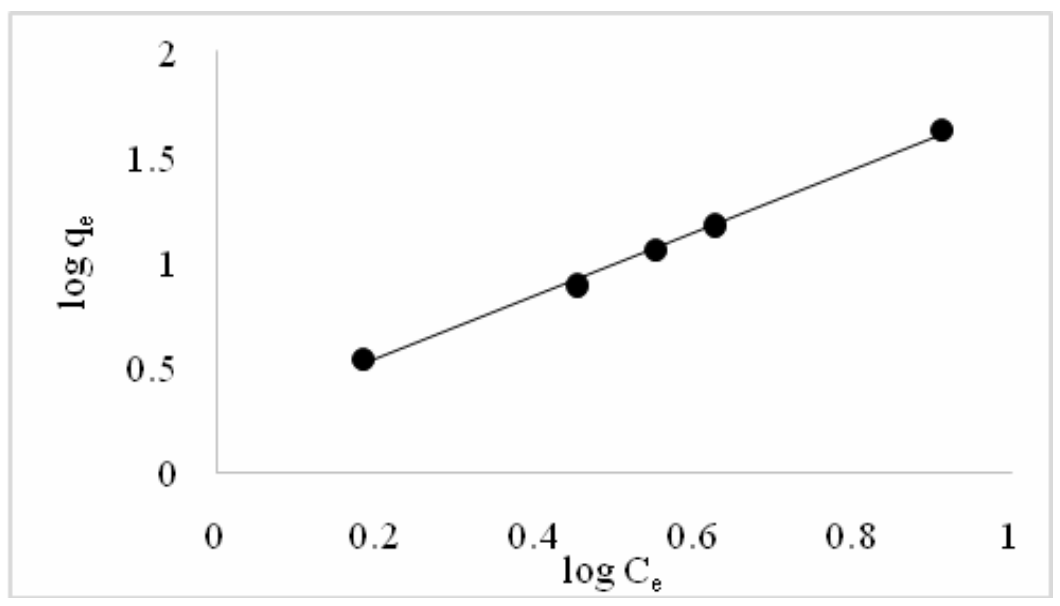

Fig. 6. Plotting of Freundlich isotherm.

Based on the values of $1 / n$ and $n$, cooperative adsorption occurred because the value of $1 / n$ was $>1[18]$; the adsorption type was chemical adsorption because the value of $n$ was $<1$ [20 cited in 19]. These results and those of the lead concentration factor, which suggested more than monolayer adsorption for the removal process, are in agreement and suggest that chemical adsorption occurred on the first layer followed by physical adsorption on the other layers.

The kinetic studies of the adsorption rate were described by pseudo first-order kinetics, as expressed by Eq. (5) and pseudo secondorder kinetics, as expressed by Eq. (6). Their applicability for describing the kinetics of the lead adsorption was determined by examination of the Egypt.J.Chem. 62, No. 1 (2019) correlation coefficients $\left(R^{2}\right)$.

Plotting the pseudo first-order model yielded a straight line with a correlation coefficient $\left(R^{2}\right)$ of 0.7573 (not shown), indicating that the adsorption rate did not follow this model.

On the other hand, plotting the pseudo secondorder model yielded a linear relationship with a $R^{2}$ value of 0.985 , indicating that the adsorption rate was described accurately by this model (Fig. 6). The value of $K_{2}$ was $0.044559 \mathrm{~g} / \mathrm{mg}$ min and the calculated value of $q_{e}$ was $20.00 \mathrm{mg} / \mathrm{g}$. Notable agreement was observed between the calculated and experimental $(19.61 \mathrm{mg} / \mathrm{g})$ values of $q_{e}$, confirming the suitability of the model for describing the adsorption rate. 


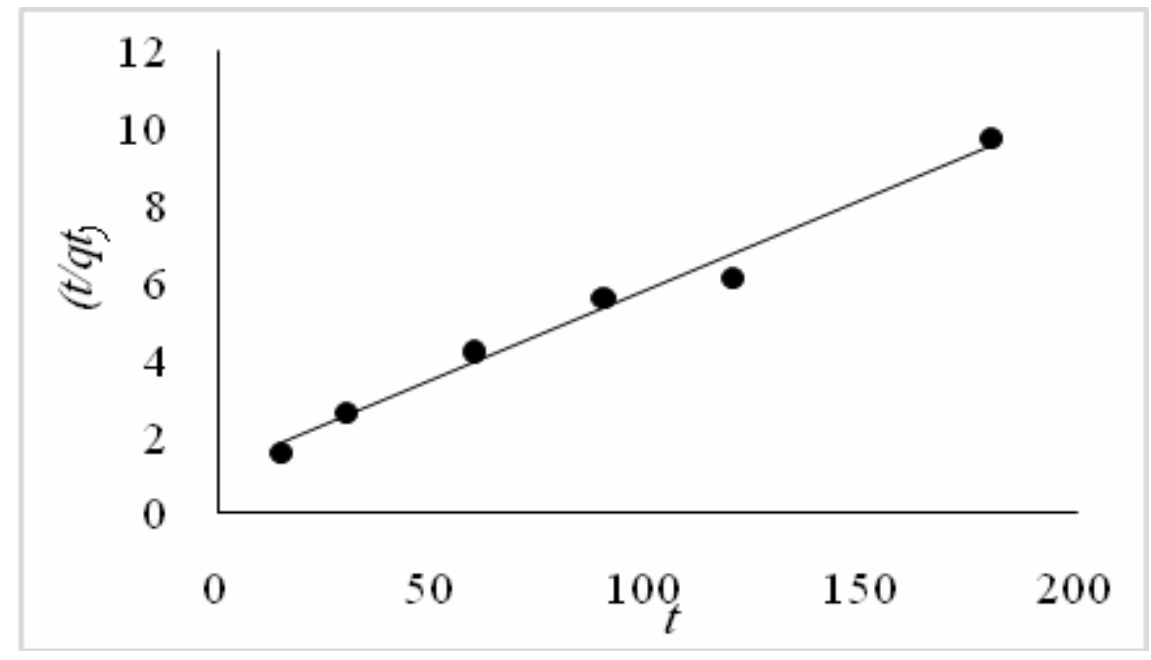

Fig. 7. Plotting of pseudo second-order model.

\section{Conclusion}

Preparation and characterization of nanocomposite films from polystyrene as a matrix and FCB as a filler was performed to investigate their ability to remove lead from an aqueous solution. The major conclusions can be summarized in the following points:

- The best conditions for removal were $30 \mathrm{ppm}$ lead with a 120 min separation time at $\mathrm{pH} 6$.

- To describe the adsorption data, the Freundlich isotherm was the best model.

- The adsorption rate followed pseudo secondorder kinetics.

Thus, it can be concluded that the prepared nanocomposite films are effective materials for the removal of heavy-metal water pollutants, specifically, the lead ion.

\section{References}

1. Hassaan M. A., El Nemr A., Madkour F. F., Environmental Assessment of Heavy Metal Pollution and Human Health Risk, American Journal of Water Science and Engineering, 2(3), 14-19 (2016).

2. Pandey N., Shukla S. K, Singh N. B., Water purification by polymer nanocomposites: an overview, Nanocomposites, 3(2) 47-66 (2017).

3. Rakesh KE, Rosy A. Bio sorption Studies of Chromium Ions with Modified Chicken Feathers Biomed, Journal of Scientific \& Technical Research, 1(7) 1-4 (2017).
4. Gupta V.K., Mittal A., Gajbe V., Mittal J., Adsorption of basic fuchsin using waste materials-bottom ash and deoiled soya- as adsorbents, Journal of Colloid and Interface Science, 319, 30-39 (2008).

5. Ahmed M., Puad N. A., Bello O.S., Kinetic equilibrium and thermodynamic studies of synthesis dye removal using pomegrant peel, Water Resources and Industry, 6, 18-35 (2014).

6. Renu, Agarwal M., Singh K., Upadhyaya S., Dohare R. K., Removal of heavy metals from wastewater using modified agricultural adsorbents, Materials Today: Proceedings, 4, 10534-10538 (2017).

7. Alshbanat M., Removal of $\mathrm{Cr}^{3+}$ ions by raw and activated carbon derived from mandarin peel, Asian journal of chemistry, 30(6), 1257-1261 (2018).

8. Saxena A., Bhardwaj M., Allen T., Kumar S., Sahney R., Adsorption of heavy metals from wastewater using agricultural-industrial wastes as biosorbents, Water Science, 31, 189-197 (2017).

9. Mohsenipour M., Shahid S., Ebrahimi K., Nitrate Adsorption on Clay Kaolin: Batch Tests, Journal of Chemistry, 2015, 1-7 (2015).

10. Uddin M. K., A review on the adsorption of heavy metals by clay minerals, with special focus on the past decade, Chemical Engineering Journal, 308, 438-462 (2017).

11. Ikram M., Ur Rehman A., Ali S., Ali S., Bakhtiar S. U.Alam S., The adsorptive potential of chicken egg shells for the removal of oxalic acid from wastewater, Journal of Biomedical Engineering and Informatics, 2(2), 118-131 (2016).

Egypt.J.Chem. 62, No. 1 (2019) 
12.Ptaszkowska-Koniars M., Goscianska J., Pietrzak R., Adsorption of dyes on the surface of polymer nanocomposites modified with methylamine and copper(II)chloride, Journal of Colloid and Interface Science, 504, 549-560 (2017).

13. Dawy M., Al-Shabanat M., Preparation and Characterization of Polystyrene/Carbon Black Nanocomposites, Journal of Applied Sciences Research, 8(3), 1358-1364 (2012).

14. Noguchi T., Inagaki Y., Miyashita M., Watanbe H., A new recycling system for expanded polystyrene using a natural solvent. Part 2 . Development of a prototype production system, Packaging Technology and Science, 11(1), 2937 (1998).

15. Lagergren, S., About the theory of so-called adsorption of soluble substances, Kungliga Svenska Vetenskapsakademins, Handlingar, 24, 1-39 (1898).

16. Ho Y.S., McKay G., Psedo-second order model for sorption process, Process Biochemistry, 34, 451465 (1999).
17. Gokila S., Gomathi T., Sudha P.N., Anil S., Removal of the heavy metal ion chromiuim(VI) using Chitosan and Alginate nanocomposites. International Journal of Biological. Macromolecules. 104, 1459-1468 (2017).

18. Alshabanat M., Almufarij R. S., Al-Senani G. M., Study on Adsorption of Malachite Green by Date Palm Fiber, Oriental Journal of Chemistry, 32(6), 3139-3144 (2016).

19. Chand P., Pakade Y. B., Removal of Pb from Water by Adsorption on Apple Pomace: Equilibrium, Kinetics, and Thermodynamics Studies, Journal of Chemistry, 2013, 1-8 (2013).

20. Mezenner, N.Y., Bensmaili, A., Kinetics and thermodynamic study of phosphate adsorption on iron hydroxide egg shell waste, Chemical Engineering Journal, 147(2-3), 87-96 (2009).

(Received 4/6/2018; accepted 4/9/2018)

\section{إزالة المعادن الثقيلة باستخدام أغشية رقيقة لمتراكبات متعدد ستيرين البوليمرية النانوية مشاعل الشبانات جامعة الأميرة نورة بنت عبدالرحمن ـ كلية العلوم ـ قسم الكيمباء ـ الرياض ـ السعودية.}

